\title{
ANA HATHERLY E A LIÇÃO ORIENTAL
}

Catarina Nunes de Almeida ${ }^{1}$

RESUMO: A obra de Ana Hatherly apresenta desde o início uma relação clara com o pensamento estético do Extremo Oriente e da Índia. Essa relação é, aliás, exposta pela autora em diversas reflexões sobre os próprios trabalhos - uma das suas marcas fundamentais é a unidade inequívoca entre poesia, pintura e caligrafia. Porém, a assimilação do saber oriental não se limita apenas a esta tríade criativa: tal experiência encontra-se comprometida também com o estudo daquela literatura, da língua chinesa, da filosofia e da espiritualidade Zen. Dado que o interesse pelo Oriente acompanhará a evolução geral do seu trabalho, torna-se essencial compreender qual a sua origem e qual o seu contributo para a construção da totalidade da obra.

PALAVRAS-CHAVE: Poesia Contemporânea, Experimentalismo, Orientalismo, Caligrafia Chinesa, Zen.

\section{ANA HATHERLY AND THE ORIENTAL LESSON}

ABSTRACT: The work of Ana Hatherly shows, from the beginning, a clear relationship with the aesthetics of the Far East and India. This relationship is, in fact, stated by the author in several insights into her own work - one of her trademarks being the fundamental bond between poetry, painting and calligraphy. However, the apprehension of the oriental knowledge is not limited to this creative triad: this experience is also committed to the study of the oriental literature, of the Chinese language, the philosophy and the spirituality of Zen. As this profound interest in Eastern culture walks side by side with her literary progression, it becomes essential to understand its origin and its contribution to the development of her works.

KEYWORDS: Contemporary Poetry, Experimentalism, Orientalism, Chinese Calligraphy, Zen.

\footnotetext{
${ }^{1}$ Bolsista de pós-doutorado no Centro de Estudos Comparatistas da Faculdade de Letras de Lisboa.
} 
A obra de Ana Hatherly manifesta desde o início um caráter multifacetado e imprevisível. O gesto criador cruza o ensaio, a poesia, a pintura, a caligrafia, a performance e o cinema. Decerto, refletir sobre cada um desses lugares separadamente será ignorar a unidade de um caminho, de um gesto absoluto, que permite definir Hatherly, como poucas vezes aconteceu no panorama cultural português, enquanto artista integral. Revisitando o percurso da autora, desde logo uma tríade criativa nos parece inevitável: um espaço significativo do seu trabalho convoca em simultâneo a poeta, a pintora e a calígrafa, isto é, convoca em simultâneo o caráter místico da escrita tal como é assumido no Oriente, onde o poeta-pintor-calígrafo constitui desde há séculos uma unidade cultural paradigmática (cf. HATHERLY, 1975, p.139). Esta unidade aparece legitimada logo nos dois primeiros parágrafos da sua "AutoBiografia Documental»: "O meu trabalho começa com a escrita"; "O meu trabalho também começa com a pintura” (cf. HATHERLY, 1992, p. 75). Essa é, diria, a (co)incidência oriental mais evidente dentro da sua obra; porém, conforme veremos, ela não surge isoladamente. A experiência oriental em Ana Hatherly está também comprometida com o estudo daquela literatura, da língua chinesa, da filosofia e da espiritualidade Zen. Em vários momentos da obra, a escrita será veículo do pensamento estético do Extremo Oriente ou da Índia. E uma vez que as (co)incidências orientais não se esgotam num ou em dois trabalhos, antes acompanham esse gesto criador que cruza várias modalidades artísticas, o Oriente pode ser entendido como uma das linhas de força mais atuantes na construção da totalidade da obra.

Segundo revela a própria autora, na introdução de Mapas da imaginação e da memória, o encontro com o saber oriental acontece por casualidade na década de 60 do século passado e, desde então, nunca mais abandonaria o estudo e aprofundamento das matérias relacionadas com aquela cultura:

Nos primeiros anos dessa década eu realizava já algumas obras gestualistas quando um dia, quase por acidente, adquiri um dicionário de inglês-chinês, que incluía uma larga secção dedicada ao chinês arcaico. É certo que nessa época eu conhecia já algumas escritas arcaicas e estava relativamente bem informada acerca da importância que, ao longo de milénios, a palavra como imagem (ou o signo em geral) teve na história da evolução das formas, culminando na actualidade nas experiências letristas e da poesia concreta que, aliás também pratiquei; mas na verdade, o meu trabalho de pesquisa sistemática da escrita começou propriamente quando iniciei o estudo metódico desse dicionário.

Ao iniciar esse estudo estava fascinada e obcecada.

À medida que ia aprofundando o meu conhecimento gestual dessa escrita eu via, na destreza crescente com que desenhava esses caracteres, na fluência do meu conhecimento deles, eu via aquilo que posso descrever como "a minha mão tornar-se inteligente"; quer dizer, experimentalmente observava, ao mesmo tempo que realizava, o acto de conhecer essa escrita [...]. (HATHERLY, 1973, p. 6). 
Com efeito, a aproximação à escrita chinesa torna-se fundamental para um apuramento crítico dos seus desenhos-escritas, mas o fascínio estende-se a outros domínios do pensamento estético oriental. Também no que concerne à palavra poética que surge apartada do labor visual (sobretudo a que se situa no ensaio poético ou no poema-ensaio, nos trilhos enigmáticos de $O$ mestre e no estilo inconclusivo e depurado das Tisanas), Hatherly declara um envolvimento com a filosofia oriental, sobretudo o Budismo Zen (cf. HATHERLY, 1992, p. 75), semelhante ao de outros escritores do Ocidente durante o mesmo período - embora em Portugal só a partir da década de 80 se comece a notar um interesse mais regular da parte dos autores. O fascínio pelo Extremo Oriente assume, para uma geração de poetas contemporâneos a Hatherly, um caráter plural, multifacetado, com influência em várias áreas do saber e da linguagem, e com um alcance não apenas estético, mas com repercussões nos hábitos, nos ideais, em suma, no próprio modus vivendi de quem se aproxima daquele universo cultural.

Voltando então a esses primeiros contactos com a escrita chinesa: é importante lembrar que eles serão responsáveis, quer em Portugal quer no Brasil, por um conjunto de manifestações poéticas de cariz visual, no qual a escrita tende a afastar-se da musicalidade e da subordinação fonética, para fazer valer a sua expressão gráfica e a sua capacidade de comunicar enquanto imagem $^{2}$. Uma das manifestações mais rigorosas dessa arte poetográfica encontrar-se-ia no próprio movimento concretista, nascido no Brasil na década de 50, mas com influência significativa na poesia experimental portuguesa. No Brasil, o contacto com a escrita chinesa provém, sobretudo, de uma fonte ocidental indireta: o ensaio de Ernest Fenollosa (1853-1908), «The Written Character as a medium for poetry», publicado em 1919 por Ezra Pound. Este ensaio, assim como a poética do Imagismo e os estudos que a acompanharam (propostos posteriormente por Pound), constituiu um forte incentivo ao Concretismo que, um pouco como na escrita ideogramática chinesa, apela em simultâneo aos atos de ler e de ver ou, se preferirmos, a um ler a imagem e a um ver o poema $a^{3}$. De fato, o contato com escritas arcaicas, como o chinês,

2 A primeira obra de poesia publicada por Ana Hatherly, Um ritmo perdido (1958), constitui ainda uma exceção a este nível. As composições não denunciam ainda essa cisão entre a palavra e a música - pelo contrário, os textos aderem explicitamente à extensa linhagem ocidental da poesia como música, numa clara apologia verlainiana (aliás, anunciada pela própria epígrafe: «De la musique avant toute chose»).

3 Em 1959 Hatherly publica, no suplemento «Artes e Letras», o primeiro artigo crítico português sobre a poesia concreta, juntamente com aquele que é considerado o primeiro poema concreto de autoria portuguesa. Nesse artigo torna-se claríssima não só a relação entre o Concretismo e aquela escrita, como a sua defesa pessoal da poesia epigramática, pautada por uma linguagem concisa e depurada, entre as novas tendências europeias: "No plano em que se situa a sua origem, a poesia concreta, como o seu nome indica, é um condensado-determinado. Ao eliminar a melodia, suspende a música, ao eliminar a gramática suspende o discurso, ao eliminar o verbo suspende o desenho. E apesar disso, pode continuar sendo musical, explícita e activa porque, suprimindo a descrição, cria a imaginação. Assim, a imagem interrompida pode ser mais sugestiva do que a completada; a ideia obscura, mais atraente do que a demonstrada; o ritmo controlado desenvolver mais força. Chegaram os poetas a um extremo de síntese através 
promoverá, para um significativo conjunto de poetas do Ocidente, a libertação da linguagem de uma certa propensão descritiva, abrindo lugar à objetividade e à síntese. Ainda assim, E. M. de Melo e Castro defende que a poesia visual de Hatherly remonta mais a uma matriz europeia ancestral do que propriamente à "noção Poundiana de Ideograma, de raiz chinesa":

Enquanto na Poesia Concreta se apela para uma leitura sintética e instantânea de "tensão de palavras-coisas no espaço-tempo", em Ana Hatherly a verbi-voco-visualidade é sobretudo de carácter processual. É uma operação que em todos os seus detalhes se propõe analiticamente perante os olhos, os ouvidos e a inteligência dos leitores, incluindo, assim, uma função crítica que é indissociável da função produtora dos textos. (CASTRO, 1992, p. 104).

Esta é uma posição aceitável, porém, não podemos ignorar que o empenho de Hatherly em estudar a escrita chinesa nos anos 60 terá consequências marcantes na sua obra, não só na prática do texto-imagem, mas também numa intensa pesquisa do signo com vista ao seu esvaziamento, a fim de o tornar operatório e livre. O que assistimos é a uma reinauguração daquela escrita, visto que, subscrevendo Raquel Henriques da Silva, "[r]apidamente, o 'trabalho de cópia' se resolve em poética pessoal, quando as amarras se soltam e a 'mão inteligente' coincide com todo o corpo" (SILVA, 2003, p. 5).

Manuel Castro Caldas afirma que é exatamente o modo incompreensível e descontextualizado com que os carateres chineses surgem pela primeira vez diante dos olhos da autora que os torna profundamente inspiradores e operacionais:

O que Ana Hatherly descobre nos anos 60, é, afinal, o que qualquer artista deste século tem de descobrir por si: uma forma cuja ilegibilidade, indecifrabilidade - cuja capacidade para veicular segredo -, a torna para o artista iminentemente operacional, isto é, passível de contaminar com o vírus da a-significância as formas decifráveis e familiares da sua cultura [...]. Todo o primitivismo, de que uma grande parte da obra visual de Ana Hatherly se deverá reclamar, adopta esta estratégia: o artista procede a uma "pilhagem» (que é o reverso de todo o colonialismo) a partir de um dado universo de formas cuja identidade própria ele (porque a desconhece) pode desrespeitar. (CALDAS, 1992, p. 108).

duma necessidade, cada vez mais premente, de descoberta do novo e do diferente. [...] Se está mais a carácter da nossa existência actual a simplicidade de modos de expressão, seja do que forem, assim se explica que a poesia tivesse evoluído no sentido do epigrama mais do que na direcção da ode e da elegia, por exemplo. Breve e conciso, equilibrado e justo, o epigrama encarna as necessidades e tendências do nosso sentir actual [...]" (HATHERLY, 1959, pp. 91 92). 
Hatherly alude diversas vezes a esta "experiência da ilegibilidade", sobretudo a propósito da coletânea de textos-visuais Mapas da imaginação e da memória (1973). Parte do seu trabalho, a partir do contacto com as escritas orientais, propõe uma leitura criadora ou uma metaleitura (cf. HATHERLY, 1975, p. 142), que coloca as formas gráficas no centro da interpretação, transcendendo assim as questões relativas ao conteúdo e ao significado dessas formas, e sugerindo um entendimento da escrita como arte do desenho ou da pintura de signos:

Com essa tentativa experimentava, por um lado, alargar o campo da leitura para fora da literalidade; por outro ainda, alargar o campo criador da própria escrita, metafórica e factualmente, pois que chamando a atenção para a escrita como desenho ou pintura de signos (tornando-a ilegível para desalojar do hábito da leitura conteudística) estava tentando restituir a escrita à sua força original, semiótica, icónica, autonomamente semântica. (HATHERLY, 1975, p. 149).

A partir daqui, uma leitura instruída da obra de Ana Hatherly passará a exigir, antes de mais, uma desaprendizagem da leitura, ou pelo menos, uma reinvenção. Numa entrevista a Maria João Fernandes, Hatherly continuava incansável nesse apelo:

[O] que fiz para a escrita [...] foi desmontar os elementos da escrita. As pessoas matavam-se para ler e eu não quero que leiam. Eu digo sempre que quero que vejam o escrito, quero que vejam a escrita. É uma maneira de desconstruir o hábito e obrigar as pessoas a uma nova leitura. Ao que chamo a reinvenção da leitura. (FERNANDES, 2000, p. 41).

De acordo com Ana Marin Martinho, autora de uma Tese de Mestrado em torno da obra visual de Ana Hatherly, o mote do trabalho será sempre essa tentativa de subtrair a escrita à sua legibilidade, devolvendo-a à imagem (cf. MARTINHO, 2007, p. 69). Em obras como Mapas da imaginaşão e da memória (1973) e O escritor (1975) - onde o aspeto formalmente visual se sobreporia ao literário - o ofício do poeta cruza-se, pois, com o ofício do pintor e do

\footnotetext{
${ }^{4}$ Num ensaio de 1975, A reinvenção da leitura, a autora refere concretamente o seguinte: "Uma importante experiência da ilegibilidade foi para mim a do estudo das escritas arcaicas, que fiz durante os anos sessenta, quando tentava descobrir experimentalmente os mecanismos da escrita. [...] Nessa época, em que o estudo da linguística moderna e da filosofia oriental dominavam o meu trabalho, tive ocasião de reflectir longamente sobre os problemas da comunicabilidade do texto, da sua legibilidade e ilegibilidade, pois constantemente estava perante textos ilegíveis para mim - por exemplo em chinês arcaico - mas que eu, não obstante, lia" (HATHERLY, 1975, p. 148). Assim, como entende José-Augusto França, acabamos por ter que considerar o fato de "que tudo tenha começado na China arcaica" como "mera desculpa, porque, depois, a autora teve que desfazer tudo", todos os signos dessa escrita, para finalmente "dizer o que nada importava que dissessem" (cf. FRANÇA, 1992, p. 90).
} 
calígrafo $^{5}$, criando-se entre eles uma dependência tão premente que não pode ser entendida senão à luz do pensamento estético do Extremo Oriente.

Desde cedo os poetas chineses e japoneses entenderam a poesia como um verdadeiro "acrescento" ao real. A poesia oriental celebra, não imita, e contribui - como ato criador, fecundo - para gerar uma nova realidade dentro do cosmos, algo que o completa. Nos Ensaios sobre a China, Simon Leys desenvolve a mesma questão, afirmando que: "A criação artística é uma participação no dinamismo do universo. A actividade artística do homem de bem faz dele um émulo e um colaborador do Criador" (LEYS, 1998, p. 190) ${ }^{6}$.

Ana Hatherly é explícita na sua adesão a estes preceitos, ao remeter as suas pinturas para a «longa tradição dos poetas-pintores que se interessaram pela dimensão plástica e gestual da escrita» (Hatherly, 1992: 83). Essa adesão é fixada, de um modo quase testamentário, em vários momentos da ars poeticae revelada na obra $A$ Idade da Escrita (1998). No «Poema-Ensaio» que inaugura o livro voltamos a ler que «a escrita é sinónimo de IMAGEM»; que «A ESCRITA / é a petrificada imagem de um percurso / do rio antigo / da seta temporal»; que «a escrita prolonga A MÃO / é o prolongamento extensíssimo da mão»; que a escrita é «onda surda» (cf. Hatherly, 1998: 8s). Ora, trabalhando a partir do paradigma oriental, Hatherly vem, similarmente, devolver ao poema o ato da escrita, recuperando assim o valor pictórico (e também gestual) da comunicação, os mais primitivos e substanciais na história da linguagem humana. Ao valorizar as possibilidades pictóricas da linguagem, a poetapintora-calígrafa sustenta uma arte que é essencialmente a da leitura, uma leitura além-palavras, na qual interpretar é transformar, é criar o texto.

Através da ars poeticae presente em $A$ idade da escrita, Hatherly vem ainda destacar-se - muito na linha das poéticas extremo-orientais - da funcionalidade mimética do poema: em «Art, The Timeless Medium» lemos que: “O poeta não quer duplicar o mundo / não quer fazer dele uma cópia: // Luta com a palavra / como Jacob lutou com o anjo [...] // E a sua mão [...] / produz / deve produzir / o que o mundo não tem / o que o mundo não diz / o que o mundo

\footnotetext{
5 Manuel Castro Caldas esboça a síntese fundamental dessa "arte da (re)união" tal como é reinventada por Ana Hatherly, na qual o estatuto do calígrafo reassume a sua centralidade: "O calígrafo teme, não exactamente o palavroso da folha em branco, ou mesmo a excessiva formalização do espaço e das coisas que o habitam e modelam, mas sim a perda de poder da palavra quando esta se dissocia da imagem, e a correspondente perda de poder da imagem quando esta se dissocia do ritual da sua inscrição e se torna totalmente 'estética'. A falta de forma da mera palavra, a falta de conteúdo da mera imagem, eis o que constringe o calígrafo, o que o faz desejar a união, a reunião, que o seu signo constitui” (CALDAS, 1992, pp. 107-108). ${ }^{6}$ Em Ideogramas na China, Henri Michaux daria conta da mesma espontaneidade criativa no que respeita à caligrafia: "Nesta caligrafia - arte do tempo, expressão do trajecto, da corrida - o que suscita admiração (para além da harmonia, da vivacidade, e dominando-as) é a espontaneidade, que pode ir quase até à explosão. Deixar de imitar a natureza. Significá-la. Por traços, arrebatamentos. Ascese do imediato, do relâmpago. Tal como são actualmente, afastados do seu mimetismo de outrora, os sinais chineses possuem a graça da impaciência, o levantar voo da natureza, a sua diversidade, a sua maneira inigualável de saber submeter-se, pular, levantarse. Assim como faz a natureza, a língua, na China, propõe-se à vista, e não decide. O seu pouco de sintaxe que deixa adivinhar, recriar, que deixa lugar à poesia. Do múltiplo sai a ideia. Caracteres abertos sobre várias direcções" (MICHAUX, 1999, p. 33).
} 
não é" (ibidem: 15). Também a poesia, na China, constitui "literalmente uma actividade de criação, e não de imitação; de resto, é disso que tira o seu prestígio único, o seu carácter sagrado" (LEYS, 1998, p. 196), embora a expressividade e o poder sugestivo dos signos, o seu efeito alusivo e as múltiplas possibilidades de leitura sejam características que, no Extremo Oriente, se estendem também à pintura. É a partir da arte pictórica sobretudo no que respeita às pinturas de paisagem - que se torna clara a comunhão entre a obra e o universo, e onde a colaboração do artista enquanto Criador universal é bem nítida. A existir "imitação" na pintura e na escrita chinesas, tratar-se-ia simplesmente da imitação desse gesto fundador, originário:

O pintor não imita as aparências visíveis do mundo exterior, mas sim a actividade do Criador universal, e remata a obra deste último; copia a Natureza, não nos seus efeitos, mas na sua operação. Aquilo que o Criador realiza à escala do universo, o pintor realiza-o à escala da sua pintura: a criação pictórica é paralela à criação cósmica, participam ambas dos mesmos ritmos e são animadas pelo mesmo "sopro" (qi); diferem pelo seu campo de aplicação, mas são actividades de natureza essencialmente idêntica. (LEYS, 1998, p. 224).

A apreensão desse gesto criador parece também implícita num poema de $A$ idade da escrita com o título «No seu jardim feito de tinta»: "arquitecto do não-útil / por entre o cosmos e o caos / o poeta olha o mundo / e reinventa-o / no seu jardim feito de tinta" (HATHERLY, 1998, p. 19). A própria ideia de não-útil parece importada de alguns textos fundadores do Zen (como a obra do sábio Zhuang-zi, onde encontramos referências à utilidade do inútil): a natureza, segundo os princípios doutrinários do Zen, vale pela sua aparente inutilidade todas as projeções a partir dela são um reflexo da personalidade e dos fins do próprio poeta, não são a natureza em si.

Este paralelo que arriscamos traçar, entre o pensamento Zen e a Arte Poética proposta por Hatherly, permitir-nos-á chegar ainda mais longe - aos vários momentos em que a sua obra parece ser veículo de ideais estéticos, filosóficos e espirituais que se afastam da tradição ocidental para trilhar outros caminhos do saber e da criatividade. Como afirma José Martins Garcia, num Posfácio às Tisanas inserido na coletânea $A$ cidade das palavras (1988), é importante considerar que a poética de Ana Hatherly constitui em si mesma uma resposta subliminar à prepotência racionalista que marca desde cedo a cultura ocidental: "Este encontro Ocidente-Oriente, razão-intuição, deduçãoiluminação, funciona como uma desinibição que, ao propor novos valores, jamais esquece que eles têm de ser, para o artista, uma questão essencialmente estética" (GARCIA, 1988, p. 135).

Em Nove incursões (1962), obra de caráter predominantemente ensaístico - ou que, para maior justiça, podemos situar no campo do ensaio poéticofilosófico - encontramos uma série de textos reflexivos que indiciam já uma 
imersão no pensamento e na cultura oriental. O texto intitulado «A Palavra Simbólica», por exemplo, deságua na importância das modalidades harmônicas da palavra - no poder oculto, mágico, do som e da vibração vocálica discorrendo, progressivamente, sobre o yoga e a prática da meditação entre as culturas do Oriente, sobre o conceito de Mantra e sobre a importância da repetição de certos sons ou palavras para o alcance da plenitude espiritual (cf. HATHERLY, 1962, pp. 130ss); algo idêntico encontramos num outro texto, «A Dinâmica da Contemplação», em que é descrita a experiência do êxtase paralela, conforme sabemos, à experiência budista do satori. E mais adiante, a autora propõe "uma dialéctica da Beleza e da Verdade" (cf. HATHERLY, 1962, p. 148), que com facilidade nos remete para a retórica formal dos diálogos entre o mestre Zen e os seus discípulos, diálogos também votados normalmente à abolição de todas as explicações lógicas da realidade e dos préconceitos, através de uma espiral de perguntas e de respostas, por vezes paradoxais e contraditórias: "Tudo é sintoma de tudo? / É. / Então tudo é Verdade? / É. / Então tudo é Beleza? / É. / Então não há Beleza nem Verdade, há só Tudo? / Há só Tudo. / E o que é Tudo? / Tudo é o que em tudo é. / Como é que se conhece? / Reconhecendo-o. / Onde? / Em tudo. / Como? / Silenciosamente" (HATHERLY, 1962, p. 150).

A apologia do silêncio - o silêncio como espaço de equilíbrio, como via privilegiada para a introspecção e usufruto dos sentidos - constitui uma das linhas temáticas mais importantes entre os poetas ocidentais que, como Ana Hatherly, se lançaram na descoberta da espiritualidade e do pensamento estético do Extremo Oriente. Essa apologia apresenta-se, desde logo, como um dos imperativos da doutrina taoista presente, por exemplo, em várias passagens do Zhuang-zi. Um dos tópicos de reflexão dentro da obra assenta, justamente, na parcialidade e ineficácia das palavras na tentativa de descrever o Tao: uma vez que "O Tao não tem limite; a palavra não é segura. É da palavra que provêm todas as distinções estabelecidas pelo homem"’ (ZHUANG-ZI, 2005, p. 27). A verdadeira sabedoria, segundo o Zhuang-zi, está no reconhecimento do indizível, na manutenção de uma certa "obscuridade" verbal perante a verdade das coisas. Se em todos os momentos da Bíblia o verbo é apresentado como elemento fecundante - ele é, por excelência, a semente espiritual - o Zen defende, pelo contrário, a impossibilidade de reduzir o Tao à linguagem. É essa impossibilidade que faz com que a Verdade se revele apenas sob a forma de paradoxos ou através de espaços deixados em branco, espaços omissos, silenciosos. O mistério, a opacidade, todas as esquinas sombrias do dizer, são garantes de equilíbrio na ponte que vai do real para as palavras.

Não é difícil aproximar esta "dialéctica da Verdade e da Beleza" da tradição budista, sabendo que um dos preceitos da iniciação é também a adoção de uma atitude inquisidora por parte do mestre, a qual, sendo repetitiva e circular, leva o iniciado até à beira do precipício mental para, finalmente,

\footnotetext{
Todas as traduções desta obra, a partir da versão italiana de Carlo Laurenti e Christine Leverd, são da minha responsabilidade.
} 
mergulhar nele. Assim, esta «dialéctica» leva-nos a refletir um pouco sobre a figura do mestre dentro das culturas do Extremo Oriente e, sobretudo, a ponderar eventuais pontos de contacto entre essa representação e a imagem do mestre revelada na poética de Ana Hatherly. $\mathrm{Na}$ obra $O$ mestre, publicada pela autora em 1963, encontramos um lugar privilegiado para ensaiar essa aproximação.

No Prefácio à terceira edição da obra, Silvina Rodrigues Lopes convida ao mesmo exercício: "Os Mestres vêm do Oriente, confundindo-se com os enigmas das suas falas; são, como Sócrates, exemplares e irónicos; impõem, como o Mestre pensado por Hegel, a sua consciência plena; como o psicanalista, estão atentos aos enigmas, com uma atenção distraída, pois sabem que todo o dizer é um meio-dizer” (LOPES, 1995, p. 11). Tal como acontece na tradição oriental, o mestre de Ana Hatherly apresenta-se como alguém que abrevia ao máximo o discurso, um homem omisso, lacônico, quase silencioso, que fala indiretamente, com rodeios, com jogos de palavras e ditos de espírito que, como refere ainda Silvina Rodrigues Lopes, "nada têm de banais, são uma espécie de porta mágica para outro espaço, colocando-nos perante um poder dizer que está para além do querer dizer" (ibidem, p. 12). Nesse sentido, a primeira ponte que podemos estabelecer entre $O$ mestre e a tradição oriental diz respeito ao reconhecimento do indizível, a que já fizemos menção - é esse reconhecimento que impele o mestre a não querer "desfazer os enigmas", porque "não se pode saber o que $O$ Mestre quer dizer, somente o que ele diz [...]" (ibidem, p. 12). Com efeito, esse trabalho defensivo em relação às palavras encontra muitas afinidades na dialética clássica entre mestre e discípulo, própria das culturas do Extremo Oriente, em que comumente nos deparamos com a metáfora do encontro falhado entre o discípulo e o eremita ou o sábio que detém a resposta suprema: "a sua presença, bem real, está mesmo ali, atestada por diversos vestígios [...]; ele próprio, contudo, permanece invisível e inapreensível" (LEYS, 1998, p. 206). O entendimento desse encontro falhado é, desde logo, a base da leitura proposta por Maria Alzira Seixo no prefácio à segunda edição:

Essa perseguição [entre Mestre e Discípula] consiste num jogo de contactos de matiz deceptivo, já porque a fuga ou a intocabilidade os suspendem invariavelmente, já porque ao nível da escrita a mensagem não existe, como se emissor e receptor se limitassem à utilização da função fática da linguagem (assegurar-se de que o outro está lá, atrair-lhe a atenção, etc.) e produzissem, portanto, falas individuais não suficientemente orientadas, sem fim, recolhendo, em paralelo, outras falas com o mesmo grau de desorientação e de inatingibilidade; assim, o encontro não se produz, a mensagem revela-se inexistente, a significação surge apenas na fenda que separa os interlocutores. [...] Daí que se fale muito, neste texto (falas curtas, incisivas, pouco discursivas), e que se não entenda nada. 
Porque o Mestre, entendido (deficientemente) como entidade comunicante, é apenas «um homem que aparece» e «O seu aparecer é que era o seu Ensinamento». (SEIXO, 1976, p. 13).

Mas existe ainda outra característica essencial da relação entre mestre e discípulo (na cultura budista, em particular) que aparece claramente individuada em Ana Hatherly: segundo aquela tradição, o valor do mestre reside na consciência da relatividade do seu saber, seja em relação à verdade, seja em relação ao discípulo ${ }^{8}$. O mestre alcança suprema sabedoria quanto mais vazio ele estiver, assumindo assim uma condição de constante abertura: porque a verdade não é um dado a adquirir, mas um objeto de interminável procura; e o discípulo, por sua vez, não é matéria inerte por moldar ou um recipiente vazio por encher - ambos, mestre e discípulo, são companheiros de aventura na busca comum de sabedoria (cf. PASQUALOTTO, 2008, p. 84).

Por último, é importante não esquecer que o livro é introduzido pelo excerto de um texto de $O$ novo ramayana. Conforme é referido num ensaio de Nelly Novaes Coelho, a escolha dessa epígrafe, desde logo, liga o romance não só à tradição oriental, como também a algo sagrado:

Ao correr das leituras do romance, essa epígrafe de abertura acaba por se revelar, como uma espécie de "seta orientadora" a indicar que, ao ser lido à luz do Zenbudismo, O Mestre revelaria a sua essencialidade última. Ao seguir essa sugestão, o Leitor descobrirá (entre outras muitas descobertas) que a presença oculta desse Espírito, ao longo da trama, é que dá organicidade/coesão à fragmentação dispersiva de sua escritura/estrutura. Transforma "fragmentos" em um "todo" coeso. (COELHO, 2010, p. 155).

Aqui chegados, faz sentido insistir na questão com que Maria Alzira Seixo inaugura o Prefácio à segunda edição de $O$ mestre: em 1963, data em que pela primeira vez foi publicada, "que textos do nosso panorama literário haviam criado os fios que proximamente pudessem suportar a concepção narrativa que esta obra desenvolve" (SEIXO, 1976, p. 9)? Na minha opinião, faz também sentido estender a pergunta a todo o trabalho de Hatherly até, pelo menos, ao início da década de 1980. O lugar ocupado pelo pensamento

\footnotetext{
${ }^{8}$ A figura enigmática presente n’ O mestre satisfaz o protótipo do sábio taoista, ao ser vazio de certezas, de juízos prévios, tão ignorante quanto a sua seguidora. Aqui parece residir o traço que exerce maior fascínio para os ocidentais: o fato de a confiança e entrega absoluta ao mestre não serem tidas como danosas para o ego de quem a ele se vincula - o aluno não procura satisfazer, através do mestre, as suas exigências pessoais, muito menos hesita em segui-lo com receio de perder o seu próprio $e \varkappa$. A obra de Hatherly resume o essencial das características do verdadeiro mestre espiritual: o abster-se de impor não só qualquer tipo de verdade predefinida, mas também os conteúdos de uma verdade em si; o ser mestre comportar uma certa ignorância e indiferença de o ser; e, por fim, a convivência do discípulo com o mestre não se basear apenas numa troca de palavras, mas também numa partilha de vida (cf. PASQUALOTTO, 2008, pp. 97-98).
} 
estético do Extremo Oriente é, indubitavelmente, um dos pontos-chave da estranheza sentida nas primeiras leituras de obras como $O$ mestre ou as Tisanas.

Por estar ciente, decerto, do caráter subversivo e inesperado da linguagem em cada obra, a autora faz acompanhar praticamente todas elas de paratextos propositivos e esclarecedores, convocando todo o percurso. Podemos entendê-los, de certo modo, como auto-explicações, não num sentido justificador da forma ou do conteúdo, mais num sentido elucidativo ou clarificador, dada a singularidade - por vezes arrojada - de cada livro. Uma aproximação inexperiente ou ingênua a alguns desses trabalhos experimentais é importante reafirmar que a obra publicada por Ana Hatherly nos primeiros vinte anos representa uma verdadeira pedrada no charco da literatura produzida no Portugal orgulhosamente só de então - podia pôr em causa a sua natureza reveladora e excepcional. Assim, também no que respeita à ponte que estabelece com o pensamento estético oriental, os paratextos e os textos críticos assinados pela autora servem de guia ao leitor mais afastado dessas matérias - é o caso deste "Prólogo», que introduz a obra $A$ cidade das palavras, onde foram compiladas todas as Tisanas até ao fragmento 222:

Se a assimilação do estruturalismo e de toda a linguística moderna, então dominante na Europa, trouxe aos meus textos dos anos 60 e 70 uma dimensão que os torna hoje historicamente paradigmáticos, a incorporação do modelo tradicional da fábula, e sobretudo o das fábulas e parábolas (ou antifábulas e antiparábolas) dos mestres do budismo Zen, que eu conheci nos anos 50 e 60 em tradução francesa e inglesa, conduziu-me à elaboração da estrutura das primeiras Tisanas. [...]

Se, quanto ao conteúdo, se poderá dizer que uma grande parte das Tisanas são fábulas (ou antifábulas, ou contos de fadas, ou mitos conhecidos reinterpretados ou subvertidos), o que faz com que esses textos sejam Tisanas é, por um lado, o seu estilo de escrita e, por outro, a sua estrutura. Se o estilo de escrita é um estilo de vanguarda, com acentuados desvios da norma, no que diz respeito à estrutura da narrativa aí pode detectar-se algo herdado da tradição Zen. Todas as Tisanas, seja qual for o seu módulo, obedecem a um princípio semelhante ao do Koan: são sempre um acontecimento-problema-interrogação-enigma, seja ele uma situação, uma citação, um comentário, etc. Todas as Tisanas dizem respeito a algo que acontece, ao significado ou à questionação do significado de um acontecer que se depara ao narrador e que frequentemente se oferece ao leitor como um desafio.

Encontra-se nas Tisanas - e isso é o que grandemente contribui para as particularizar - algo dessa «indeterminação deslizante» atribuída ao ensinamento Zen, associado a uma técnica de destruição da certeza. Mas grande parte dessa consciência da «indeterminação deslizante» também decorre de uma meditação sobre a natureza da linguagem e da comunicação pela linguagem, que tem por base pressupostos da linguística moderna, de cujo estudo também me ocupei.

(HATHERLY, 1988, pp.7-8) 
De fato, Tisanas, com uma primeira versão publicada em 1969, constitui uma obra cuja natureza, até hoje, parece difícil de definir, mas cujo envolvimento com o pensamento estético do Zen parece evidente. Entre as afinidades mais marcantes que podemos encontrar na obra, relativamente à linguagem formal do Zen, destaca-se sem dúvida essa reelaboração do Koan budista de que a autora dá conta. No fragmento 275 encontramos, aliás, uma alusão directa ao conceito: "Voltemos ao Koan. O que é o sentido? Uma mala fechada que nunca teve fecho. Eis a ironia e a humildade" (HATHERLY, 2006, p. 110).

Os Koan eram aforismos ou questões postas pelos mestres budistas aos noviços; na sua essência, traduziam sentenças contraditórias que comprovavam desde logo o desinteresse do Zen por um conhecimento decisivo do mundo exterior e, mais ainda, pela expressão desse conhecimento através das palavras. Os diálogos gerados a partir destas sentenças estavam repletos de elementos irracionais, paradoxais e até grotescos, uma vez que a sua finalidade era ensaiar a capacidade dos discípulos compreenderem aquilo que ultrapassa as categorias do pensamento lógico e discursivo. Assim, não é difícil aproximar algumas Tisanas da estética formal do Koan, sabendo que um dos seus preceitos é precisamente a adoção de uma atitude inquisidora, a qual, sendo repetitiva e circular, leva o iniciado até à beira do precipício mental para, finalmente, mergulhar nele. Nas interrogações presentes em alguns dos fragmentos pode estar estabelecida uma meta análoga, que reformula lugares-comuns, retirando deles uma renovada visão: "Sento-me à porta de casa e penso. o céu onde começa? é imediatamente acima do chão? do outro lado da minha casa passa o rio. um pescador espera paciente enquanto outro se prepara para regressar. deito-me no chão e mergulho a cara na terra" (ibidem, p. 41). Podemos associar a este fragmento a mesma dissolução da lógica na tentativa de descrever o Tao, típica dos Koan, embora a aproximação ao Zen não se fique por aqui. As Tisanas tocam ainda outros tópicos que marcam aquela doutrina, entre eles:

1. A problemática do indizível:

O autor e o leitor: estamos no limiar do prazer. Um de cada lado com anfitriões esperando tensos. Vivemos a problemática do segredo - se for divulgado deixa de existir se não for torna-se um horrível tormento. Alguns mestres dizem que o próprio prazer é não poder ser dito. (ibidem, p. 69)

2. O abandono dos bens materiais:

O património das coisas. Ter o quê? Um árduo percurso obriga-nos a deitar fora o que é desnecessário. Quando tudo escurece nada mais interessa. E vamos embora sem pedir licença.

(ibidem, p. 156) 
3. A abolição de metas e fins para alcançar o saber e a felicidade:

Era uma vez uma pessoa que procurava a sabedoria. Tinham-lhe dito que para a atingir tinha sempre que aceitar e recusar ao mesmo tempo tudo o que lhe fosse oferecido, dito ou mostrado. Quando perguntava por onde era o melhor caminho e lhe diziam "é por ali" ela devia seguir imediatamente nesse sentido e depois no sentido contrário. Tendo assim percorrido todas as direcções indicadas e as não indicadas, sem mais caminhos a percorrer, sentou-se no chão e começou a chorar. Sem saber, tinha chegado.

(ibidem, p. 138)

Por último, o fato de ser uma obra intencionalmente inacabada, um espaço aberto e em contínua atualização, também se liga a algumas concepções estéticas do Zen, sobretudo as que negam a perfeição absoluta ou o caráter definitivo da obra de arte: assim passamos das primeiras 39 Tisanas (publicadas em 1969) a 63 Tisanas (1970), mais tarde 176 Tisanas (1978), 222 Tisanas (1988), até à versão última de 463 Tisanas (2006).

Ainda no contexto desta assimilação, direta ou indireta, da cultura do Extremo Oriente, não podemos descurar o papel da tradução no estudo de certos modelos poéticos. Sobretudo a tradução de poesia chinesa - realizada quase sempre por poetas - a partir da década de 90, conhece algum destaque em Portugal, quer sob a forma de recolhas coletivas, quer na publicação de obras individuais de autores clássicos. Entre as versões poéticas propostas por autores contemporâneos, inclui-se $O$ vagabundo do Dharma - 25 poemas de HanShan, publicado por Ana Hatherly em 2003. Os poemas do mestre chinês, fortemente inspirados pelo Taoismo e pelo Budismo Zen, são trabalhados a partir da versão francesa, mas apresentam não só a particularidade de fazerem acompanhar cada texto de caligrafia na língua original como nos oferecem, mais uma vez, nos paratextos introdutórios, importantes pistas para a interpretação das cumplicidades e motivações que levaram a autora a aproximar a sua própria poesia da poética oriental. No «Prefácio à Presente Edição», Hatherly define a sua tradução como sendo, no essencial, um exercício de "reciclagem" da escassez e da simplicidade daquela escrita e da natureza elíptica e inesgotável dos versos:

Renunciando a qualquer tentativa de reconstituição métrica, o que eu fiz foi apenas seguir fielmente a indicação do número de versos, emparelhando-os tanto quanto possível, evitar uma escrita discursiva e reduzir a um mínimo de pontuação, o que conferirá às minhas versões uma tonalidade despojada, por vezes um tanto lacónica, que tem a ver com o espírito do ideograma e com a linguagem simples do texto original.

(HATHERLY, 2003, p. 25) 
A publicação desta versão poética corresponde a uma intromissão profunda na matéria oriental, movida por um esforço voluntário de aperfeiçoamento e de reflexão; ao mesmo tempo, corresponde também a um ensaio da vitalidade com que essa matéria vibra na sua própria língua e das possibilidades de a fixar na sua voz poética, autoral.

Depois desta leitura, algo panorâmica, da obra de Ana Hatherly a partir da relação literária que se estabelece com o pensamento do Extremo Oriente ou da Índia, somos levados a rever uma vez mais o tópico de abertura desta reflexão: Ana Hatherly apresenta-se como uma artista integral. As (co)incidências orientais que se deixam adivinhar pelo meio de um longo percurso, não são mais do que exemplos de uma relação privilegiada entre diferentes artes, e ressaltam de um entendimento da obra enquanto "objeto total" - como vimos, em Ana Hatherly, poesia, caligrafia e pintura partilham o mesmo eixo criativo e não podem ser "lidas" separadamente", pois «caligrafia e silêncio, movimento e repouso, mancha e página em branco compõem uma só experiência estética» (MARTINHO, 2007, p. 52).

Desta forma, a integração de certos aspetos formais da poética chinesa é também visível na própria anatomia e concepção gráfica de alguns livros de Hatherly - exemplares são, desde logo, as capas, contendo recorrentemente caligramas da autora. A sobriedade do livro, a textura do papel ou a inserção da caligrafia chinesa, são preceitos que se fidelizam à estética formal que os inspira e que redimensionam a abordagem do poético na sua totalidade. $\mathrm{Na}$ «AutoBiografia Documental», Hatherly confirma esse mesmo fato:

Mapas da Imaginação e da Memória, como já referi, é uma colectânea de obras realizadas entre 1971 e 1973, muito influenciadas pelos meus estudos orientais. [...] O design é meu. Fizeram-se duas tiragens, que apenas diferem na capa, uma das quais em forma de envelope atada com uma fita de seda preta, que acentuava o seu cunho orientalizante.

(HATHERLY, 1992, p. 84)

O elogio da estética oriental ressoa, pois, dentro e fora do texto - é a obra como um todo. Em vários livros, o trabalho de edição é notoriamente sensível ao fato de, na poesia clássica do Extremo Oriente, a palavra ser inseparável da sua expressão visual (ou se preferirmos subscrever Simon Leys:

\footnotetext{
${ }^{9} \mathrm{Na}$ verdade, a profusão artística que encontramos na obra visual de Ana Hatherly favorece uma certa ambiguidade quanto à natureza do suporte e dos materiais se nos reportarmos apenas à tradição ocidental, uma vez que, conforme nota Manuel Castro Caldas, ambos são excêntricos quer em relação ao mundo das letras quer ao mundo das artes plásticas: «Por um lado, estamos inequivocamente próximos do mundo das letras. A escala preferencial, quase exclusiva, destas obras é a do pequeno cartão, do bilhete-postal, da folha de caderno de apontamentos (apenas raramente a da folha de bloco de esquiços). Os materiais utilizados são, por sua vez, quase exclusivamente a tinta de caneta ou tinta da china (menos frequentemente a caneta de feltro e, menos ainda, a esferográfica), quase sempre nas cores tradicionais da escrita corrente: preto, azul, por vezes o sépia, castanho ou vermelho. Finalmente, em muitas das obras onde pensamos, à primeira vista, distinguir apenas doodles ou uma espécie de mock writing, a presença efectiva de palavras e frases legíveis surpreende-nos» (CALDAS, 1992, p. 106).
} 
«Os princípios estéticos e os procedimentos da poesia são de ordem pictórica; os princípios estéticos e os procedimentos da pintura são de ordem poética» (LEYS, 1998, p. 184)). Reportando-se à tradição chinesa, Leys mostra assim que a apresentação material da poesia é, por si só, reveladora da sua natureza pictórica e vice-versa: «Ao passo que em geral, pela sua própria natureza, toda a poesia se exprime de um modo sucessivo, se desenrola no tempo, a poesia chinesa, essa, esforça-se por dispor as palavras no espaço» (ibidem, p. 184).

Em Ana Hatherly, a compreensão desta dinâmica consubstancia-se em obras híbridas, que fazem da palavra uma matéria que atravessa outras formas de expressão, que não apenas a poesia. A escrita é devolvida à sua natureza originária, de arte manual, e o elemento visual passa a ser cúmplice do texto. Torna-se, então, evidente que um poema que bebe da fonte oriental não habita apenas o tempo, mas também o espaço. Um livro onde poesia, pintura e caligrafia se harmonizam está mais próximo de recriar um universo genésico que se quer completo, orgânico e a quatro dimensões.

\section{BIBLIOGRAFIA ATIVA}

HATHERLY, Ana. Um Ritmo Perdido. Lisboa: Edição do Autor, 1958. Nove Incursões. Lisboa: Sociedade de Expansão Cultural, 1962. Mapas da Imaginação e da Memória. Lisboa: Moraes Editores, 1973. O Escritor (1967-1972). Lisboa: Moraes Editores, 1975. “A Reinvenção da Leitura”, In PO.EX. Textos Teóricos e Documentos da Poesia Experimental Portuguesa. Lisboa: Moraes Editores, 1981.

"O idêntico inverso ou o lirismo ultra-romântico e a poesia concreta", In PO.EX. Textos Teóricos e Documentos da Poesia Experimental Portuguesa. Lisboa: Moraes Editores, 1981. A Cidade das Palavras. Lisboa: Quetzal Editores, 1988. “Auto-Biografia Documental", In Ana Hatherly: obra visual 19601990. Lisboa: Centro de Arte Moderna Fundação Calouste Gulbenkian, 1992. A Idade da Escrita. Lisboa: Edições Tema, 1998. O vagabundo do Dharma - 25 Poemas de Han-Shan. Lisboa: Cavalo de Ferro, 2003.

463 Tisanas. Lisboa: Quimera, 2006.

\section{BIBLIOGRAFIA PASSIVA}

CALDAS, Manuel Castro. "O Estatuto do Calígrafo. Obra Visual de Ana Hatherly”, In Ana Hatherly: obra visual 1960-1990. Lisboa: Centro de Arte Moderna Fundação Calouste Gulbenkian, 1992.

CASTRO, E.M. de Melo e. "Da Poesia Concreta", In PO.EX. Textos Teóricos e Documentos da Poesia Experimental Portuguesa. Lisboa: Moraes Editores, 1981. 
“(H)A VER ANA HATHERLY. Notas sobre a Poesia Visual”, In Ana Hatherly: obra visual 1960-1990. Lisboa: Centro de Arte Moderna Fundação Calouste Gulbenkian, 1992.

COELHO, Nelly Novaes. "O Mestre Revisitado - Romance-farsa ou Ritual Iniciático?”, In Leonorama - Volume de Homenagem a Ana Hatherly. Lisboa: Edições Colibri / Faculdade de Ciências Sociais e Humanas da Universidade Nova de Lisboa, 2010.

FERNANDES, Maria João. "Entrevista a Ana Hatherly", In Arte Teoria, n. 1. Lisboa: Faculdade de Belas-Artes da Universidade de Lisboa, 2000.

FRANÇA, José-Augusto. "Para que o barroco depois viesse...", In Ana Hatherly: obra visual 1960-1990. Lisboa: Centro de Arte Moderna Fundação Calouste Gulbenkian, 1992.

GARCIA, José Martins. "Enigmas da Circularidade (sobre Tisanas, de Ana Hatherly)", In A Cidade das Palavras. Lisboa: Quetzal Editores, 1988.

LEYS, Simon. Ensaios sobre a China. Trad. António Gonçalves. Lisboa: Livros Cotovia, 2005.

LOPES, Silvina Rodrigues. "O Espírito e a Letra", In O Mestre. $3^{a}$ ed.. Lisboa: Quimera Editores, 1995.

MARTINHO, Ana Marin. Quando o desenho encontra a escrita: território contaminado a partir da obra de Ana Hatherly. Tese de Mestrado em Desenho. Lisboa: Faculdade de Belas-Artes da Universidade de Lisboa, 2007.

MICHAUX, Henri. Ideogramas na China. Trad. Ernesto Sampaio. Lisboa: Edições Cotovia, 1999.

PASQUALOTTO, Giangiorgio. East \& West. Identità e dialogo interculturale. $2^{\mathrm{a}}$ ed.. Veneza: Marsilio Editori, 2008.

SEIXO, Maria Alzira Seixo. “Amor e Pedagogia - prefácio a 'O Mestre' de Ana Hatherly”, In O Mestre. 2a ed.. Lisboa: Moraes Editores, 1976.

SILVA, Raquel Henriques da. "Ana Hatherly: os campos abertos do (in)dizível", In Ana Hatherly: a mão inteligente. Lisboa: Quimera Editores, 2003. ZHUANG-ZI. Zhuang-zi. $4^{a}$ ed.. Milão: Adelphi Edizioni, 2005.

Artigo recebido em 08 de Agosto de 2013.

Artigo aprovado em 06 de Novembro de 2013. 